\title{
Aplicação de Conceitos e Práticas de Atividades do Movimento Maker na Educação Infantil - Um Relato de Experiência para o Ensino Fundamental 1
}

\author{
Roberta Emile Lopes de Oliveira ${ }^{1}$, Camila A. M. dos Santos ${ }^{1}$, \\ Edmar E. P. de Souza ${ }^{1}$
}

\author{
${ }^{1}$ Centro Universitário Ruy Barbosa Wyden \\ Caixa Postal 41940-320 - Salvador - BA - Brasil \\ robertaemile@gmail.com, camila.santos@frb.edu.br, edmar.souza@frb.edu.br
}

\begin{abstract}
Playful activities based on the practice of scientific teaching can contribute to increase the performance of the essential skills of children. This work presented experience reports of the application of activities based on the Maker movement, worked on early childhood education. It seeks to understand the importance of working motor development; the ability to communicate and speak; social relations; emotional intelligence; the capacity for adaptation and cognitive development. The article seeks to report how the Maker culture fosters learning aligned with a pedagogical proposal that can be implemented in public and private schools in the country.
\end{abstract}

Resumo. Atividades lúdicas fundamentadas na prática do ensino científico podem contribuir para o aumento do desempenho de habilidades essênciais de crianças. Esse trabalho tem como objetivo, apresentar relatos de experiência da aplicação de atividades baseadas no movimento Maker, trabalhadas na educação infantil. Busca compreender a importância de se trabalhar o desenvolvimento motor; a capacidade de comunicação e fala; as relações sociais; a inteligência emocional; a capacidade de adaptação e desenvolvimento cognitivo. $O$ artigo busca relatar como a cultura Maker fomenta aprendizados alinhados a uma proposta pedagógica que pode ser implementada em escolas públicas e particulares do país.

\section{Introdução}

O ensino fundamental é o momento para aprimoramento de habilidades e desenvolvimento de aptidões. São os pequenos aprendizados do dia a dia que trabalharão habilidades motoras, de linguagem, sociais, afetivas, adaptativas e também cognitivas. Em um projeto pedagógico é necessário que sejam estabelecidas atividades em cada série escolar, visando o aperfeiçoamento de tais capacidades.

Os modelos atuais de educação, em sua maioria, são formalizados e adotam métodos que carecem da motivação pela descoberta, pela experiência de fazer e construir. Diante disso, nota-se a necessidade do uso de tecnologias no cotidiano escolar, com foco na aprendizagem criativa e na realização de projetos particulares ou coletivos que incentivem a inovação que melhorem a capacidade tátil das crianças e garantam a obtenção de novos conhecimentos. A motivação intrínseca, centrada na tarefa, é importante para 
VII Congresso Brasileiro de Informática na Educação (CBIE 2018)

Anais do XXIV Workshop de Informática na Escola (WIE 2018)

desenvolvimento da criatividade, uma vez que as pessoas estão mais propensas a responder criativamente à uma dada tarefa, quando estão movidas pelo prazer de realizá-la [de Alencar 2003].

É essencial que ao realizar essas atividades as crianças se movimentem, pesquisem, sejam predispostas a se mobilizar e passem a ter uma inclinação para buscar aprender por toda vida [Cheroglu 2014]. A Educação Infantil como etapa inicial da educação básica é importante para o desenvolvimento das habilidades que possibilitarão a compreensão e interiorização do mundo humano pela criança, neste sentido é essencial trabalhar atividades operacionais, pois é a partir da interação com o meio, determinado por um ato intencional e dirigido do professor que a criança aprende [Vygotski 1998].

No cenário atual cada vez mais moderno, as tecnologias são um fator impulsionador no que tange ao desenvolvimento profissional do aluno e as suas habilidades cognitivas. O professor torna-se então um mediador de extrema importância para o aprendizado. A importância da mediação do professor nesse processo, a relação do aluno com os fatores externos e os métodos utilizados estão extremamente alinhados com o desenvolvimento da aprendizagem.

De acordo com a teoria sócio-histórico-cultural Vygotskyana, a relação entre o homem e a sociedade, cultura e sua história de vida, é um fator que compreende situações de aprendizagem, permitindo a definição da competência da criança e de suas futuras conquistas, assim como a elaboração de estratégias pedagógicas que auxiliem neste processo. O desenvolvimento e aprendizado proposto por Vygotsky [Vygotski 1987] referese ao aprendizado que quando adequado, ou seja, de forma organizada, resulta em um desenvolvimento mental eficaz, coloca em movimento processos de desenvolvimento que seriam impossíveis de outra maneira. $\mathrm{O}$ indivíduo então se apropriará de conhecimentos exteriorizados observada a sua interação com o meio. É necessário refletir acerca de novas práticas que estão sendo implementadas no contexto pedagógico de algumas escolas e que são eficazes no que se diz respeito ao papel do professor como mediador e a interação que o aluno produz com seus colegas ao projetar e sistematizar suas ideias em grupo. Tais práticas tornam-se capazes de resultar em um desenvolvimento mental eficaz, dado que o indivíduo se apropria das interações e mediações para construir e projetar. Por tanto, a Cultura Maker de Educação com a produção mão na massa, possibilita ao indivíduo desenvolver habilidades e despertar a aprendizagem.

\subsection{Desenvolvimento de Habilidades Motoras}

As habilidades motoras são indispensáveis para a criança. Desde o início do seu desenvolvimento ela aprende a segurar objetos, comer sozinho, e etc. Na medida em que ela cresce, desenvolve outras habilidades, aprende a segurar o lápis, desenhar, e utilizar seus músculos para realizar atividades com um propósito planejado.

Desenvolver habilidades como desenhar, cortar, pintar, apertar um parafuso ou utilizar ferramentas são atividades simples, mas que ao serem praticadas contribuem significativamente para o desenvolvimento motor infantil [de Alencar 2003]. Tais atividades trabalhadas desde a infância focando no desenvolvimento motor possibilitam à criança um melhor progresso em outras práticas com a mesma base, como tocar um instrumento, dançar ou saber se portar. O processo de aprendizagem relaciona corpo e mente, atuando na relação entre outros corpos, objetos e espaço. A escola deve realizar atividades lúdicas 
VII Congresso Brasileiro de Informática na Educação (CBIE 2018)

Anais do XXIV Workshop de Informática na Escola (WIE 2018)

que permitam ao aluno a capacidade de manipulação de ferramentas contribuindo para seu desenvolvimento tátil.

\subsection{Desenvolvimento da Linguagem}

A habilidade de a criança entender e usar a linguagem falada inicia-se ao dizer suas primeiras palavras se perpetua durante sua infância. É graças a linguagem que a criança tornar-se capaz de invocar situações não atuais, libertando-se então das fronteiras do espaço próximo e presentes, ou seja, saindo do campo perceptivo [Piaget 2011].

A partir dos quatro anos a habilidade de formar diálogos e expressões já é bastante desenvolvida. Durante o Ensino Fundamental 1 é importante que sejam exploradas tais capacidades na criança, propondo atividades lúdicas que promovam a experiência de criar diálogos usando a criatividade e estimule a capacidade de se comunicar e falar em público.

\subsection{Desenvolvimento social, emocional e afetivo}

A criança se desenvolve de acordo com a aquisição de aprendizagem com o meio em que está inserida. É no ambiente escolar onde a criança irá manifestar o seu temperamento. As atividades em grupo possibilitam a apresentação dessas características. O ideal é que durante essas atividades sejam trabalhadas algumas ações emocionais negativas das crianças, como o excesso de introversão, extroversão, irritabilidade, timidez, entre outras, para que ao serem corrigidas essas características, sejam geradas consequências positivas em outros aspectos de perspicácia da criança [Piaget 1986].

A escola deve se preocupar não apenas em ensinar o conteúdo programático, mas deve haver um equilíbrio em relação ao ensino e a preocupação no desenvolvimento social, de forma que a educação da criança seja desenvolvida de maneira integral, se preocupando com todos os aspectos [Cheroglu 2014].

\subsection{Desenvolvimento adaptativo e cognitivo}

A inteligência não aparece, de modo algum, num dado momento do desenvolvimento mental, como um mecanismo completamente montado e radicalmente diferente dos que o precederam [Piaget 1986]. Apresenta, pelo contrário uma continuidade admirável com os processos adquiridos ou mesmo inatos respeitantes à associação habitual e ao reflexo, processos sobre os quais ela se baseia, ao mesmo tempo que os utiliza.

O processo cognitivo infantil tem início desde o seu nascimento, mas é desenvolvido proveniente de reflexos e hábitos adquiridos ou congênitos. O processo de inteligência deriva-se de respostas do ambiente em que a criança está inserido e da ação que o sujeito executa sobre as informações que recebe, transformando as informações em conhecimentos. No processo de constituição da inteligência infantil, adquirir conhecimento está extremamente relacionado com adaptação ao meio e a ação da criança sobre o mundo. Dessa forma, é necessário que o ensino escolar possibilite ao aluno o interesse pela pesquisa, pela observação, indagação e busca constante em conhecer. Para que o aluno seja o princípio ativo no processo de construção dos seus conhecimentos.

As atividades propostas pela cultura maker, desenvolvem habilidades motoras, pois propõem o aluno colocar a mão na massa. Permitem que ele aperfeiçoe sua linguagem por motivar a apresentação de projetos, o falar em público e a participação durante a aula, seja trazendo dúvidas e ideias ao orientador ou discutindo com os colegas aspectos 
VII Congresso Brasileiro de Informática na Educação (CBIE 2018)

Anais do XXIV Workshop de Informática na Escola (WIE 2018)

referente a concepção do projeto. O lado social, emocional e afetivo também é trabalhado quando o aluno participa de trabalhos em grupo, interage, troca informações, aprende a lhe dar com os múltiplos personagens da equipe, se frustra por não conseguir na primeira vez, mas persiste na sua tarefa até conquistar seu objetivo. Na cultura maker, o aluno desenvolve seu lado cognitivo por ser construtor das suas próprias ideias, é criativo, capaz de inovar, aprender a processar informações, métodos e a aplica-los para um determinado fim. É notório que a cultura maker não está limitada apenas a trazer novos conhecimentos ou ao uso de recursos tecnológicos, mas também irá propiciar que o aluno desenvolva habilidades e estimule seu processo de aprendizagem.

\section{A proposta da cultura Maker como mudança para educação}

Ao longo da história da educação infantil no Brasil, é possível notar inúmeras mudanças no que se refere aos modelos de aprendizado. Em paralelo a isso vemos uma constante busca por inovação tecnológica na sociedade. As atividades desenvolvidas no Ensino Fundamental 1 no Espaço Maker tem como objetivo alinhar esses dois ideais através do desenvolvimento de projetos que relacionam o aprendizado em sala de aula com tecnologia [Machado and Adalberto 2016].

A cultura maker tem como principal objetivo Faça Você Mesmo (ou Do-ItYourself, em inglês), através de ferramentas tecnológicas como a placa Arduíno, impressoras 3D, cortadoras a laser e kits de robótica, prototipação e fabricação de produtos, soluções e projetos [Duarte et al. 2017]. Saindo da sala de aula e indo para laboratórios, os adeptos da cultura maker visam troca de experiências em grupo, estímulo a capacidade inventiva, e a capacidade empreender e pesquisar [Pinto et al. 2016].

Nos tempos atuais existem novas maneiras de fazer a criança pensar, aprender, aumentar sua percepção e imaginação através de construções lúdicas, voltadas para a tecnologia, que são utilizadas para jogos e brincadeiras no cotidiano com um contexto pedagógico. As escolas que inserem as crianças nesse contexto desde o Ensino Fundamental 1 possibilita a criação de protótipos colocando a mão na massa. Garantindo mais motivação no ambiente escolar, e contato com a tecnologia.

Capacitar as crianças em suas especificidades, analisando e refletindo sobre suas interações com as mídias, é uma forma de criar condições para suas participações. O principal desafio é fazer com que os alunos entendam para quê eles estão utilizando esses materiais, é preciso entender o objetivo [Buckingham 2007]. Para isso as atividades realizadas são contextualizadas com algum assunto que eles estão aprendendo no seu conteúdo programático. Também é abordada alguma curiosidade física ou científica propiciando experiências em assuntos que estão por vir. O objetivo é fazer com que, ao chegar nas séries em que os alunos estudarão outras ciências eles já estejam motivados pela pesquisa e já tenham tido experiências práticas [Rafaela Samagaia 2015].

Todos os objetivos, assuntos, curiosidades e contextos são alinhados de acordo com a capacidade cognitiva de cada série e a aptidão para construir determinados protótipos. Além de possibilitar esse conjunto de novos conhecimentos e incentivo a pesquisa, a cultura Maker trabalha em aspectos que podem não ser percebidos pelas crianças, mas que estão sendo desenvolvidos no seu processo de evolução. A sua capacidade motora, social e emocional, sua adaptação ao meio e desenvolvimento cognitivo.

Segundo Martins (2001), Os projetos contribuem para que os alunos participem e 
VII Congresso Brasileiro de Informática na Educação (CBIE 2018)

Anais do XXIV Workshop de Informática na Escola (WIE 2018)

se envolvam em seu próprio processo de aprendizagem e o compartilhem com outros colegas, como também exijam que o professor enfrente desafios de mudanças, diversificando e reestruturando, de forma mais aberta e flexível, os conteúdos escolares. [Martins 2001]

As atividades realizadas possibilitam o aluno expandir sua capacidade criativa, entender métodos, meios e instrumentos necessários para se realizar uma atividade, dominando um conjunto de técnicas para executá-las. Além de atividades individuais são realizados projetos em grupo visando melhorar habilidades, integrar valores, estimular no aluno a capacidade de decidir, debater, avaliar e ao mesmo tempo ser dedicado e disciplinado para conclusão do projeto.

\section{Metodologia}

Com o início das aulas em 2018 foram iniciadas as práticas no laboratório infantil denominado Espaço Maker. Este espaço é separado exclusivamente para o Ensino Fundamental 1, devido ao fato que a proposta dos protótipos a serem construídos é diferente do Ensino Fundamental 2. As aulas possuem duração de 50 minutos e as turmas foram divididas em dois grupos, possuindo encontros quinzenais, as crianças do Fundamental 1 precisam de mais assistência para o desenvolvimento das atividades, então o mais viável foi diminuir o tamanho das turmas, além da restrição do tamanho do laboratório.

Esse espaço possui diversas ferramentas, serra, lima, lixas, tesouras, estiletes, placas de arduino, pilhas, leds, cola-quente entre outros materiais diversos para criação dos protótipos. Além dessas ferramentas dispomos de dois equipamentos que são a Impressora 3D e Cortadora a Laser. Devido a idade das crianças, muitas das ferramentas são utilizadas apenas com auxílio ou supervisão dos professores. Os equipamentos com mais complexidade, como a impressora e cortadora, são utilizados pelo professor para disponibilizar itens para as aulas e fazendo demonstração. O trabalho desenvolvido foi elaborado por estudante de graduação em Engenharia, como parte do seu estágio curricular, em um colégio privado de ensino, na cidade de Salvador/BA. A vivência universitária trouxe a capacidade de propor atividades para as crianças além do material que nos foi entregue por uma empresa externa. Com os conhecimentos adquiridos pela engenharia foi possível produzir ideias contextualizadas com assuntos voltados a tecnologia, ciências e ao desenvolvimento mão na massa. Todas as atividades foram e estão sendo propostas de acordo com a capacidade engenhosa das crianças, e incentivando a explorarem tais capacidades.

A partir desses insights novas propostas estão sendo planejadas, montadas e sendo adequadas ao plano programático do Maker. No próximo tópico serão citadas algumas das atividades desenvolvidas.

\section{Resultados - Relatos de Experiência}

\subsection{Quinto ano}

\subsubsection{Conceitos sobre Velocidade}

Uma das atividades desenvolvidas com o quinto ano do ensino fundamental, foi a criação de um protótipo Demonstrador de Velocidade, o objetivo principal do projeto foi ensinar o conceito da velocidade e a sua relação entre espaço e tempo. Assim como em um carro, a potência do motor determina a velocidade com que a roda gira, o protótipo segue 
VII Congresso Brasileiro de Informática na Educação (CBIE 2018)

Anais do XXIV Workshop de Informática na Escola (WIE 2018)

a mesma relação. Além disso, foram abordadas curiosidades em relação a velocidade e para tornar a atividade mais lúdica para crianças foi utilizado no protótipo personagens relacionados a velocidade.

Essa atividade foi desenvolvida em duas aulas de 50 minutos, na primeira além de abordar os conceitos gerais foi possível transmitir aos alunos experiências práticas com desenho geométrico, entendendo o que é raio, diâmetro e centro da circunferência. Os alunos puderam personalizar o seu desenho o tornando único, desenvolvendo sua capacidade criativa.

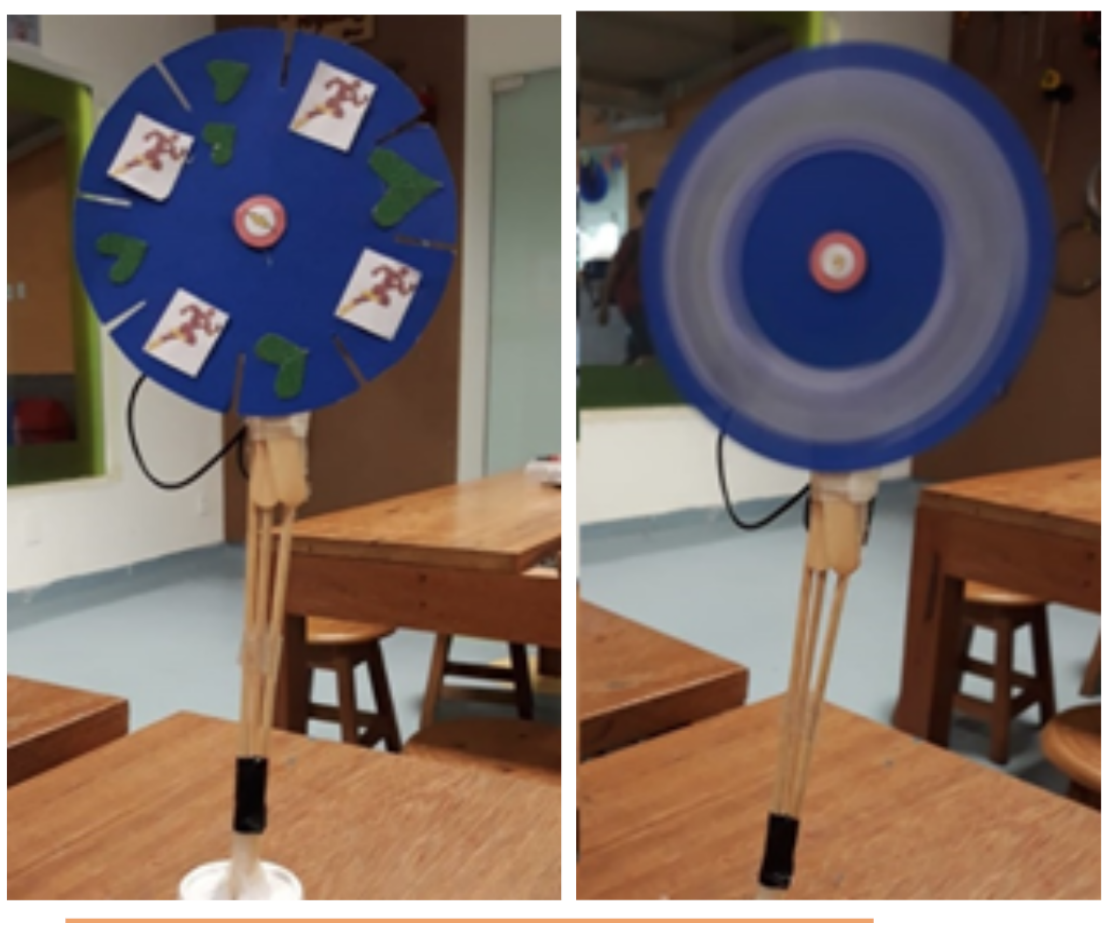

Figura 1. Protótipo para apresentação dos conceitos da Velocidade.

$\mathrm{Na}$ aula subsequente realizou-se a montagem do protótipo, inicialmente foi explicado o funcionamento do circuito elétrico simples; os polos positivos e negativos da bateria e o seu desempenho como fonte de energia; o motor como atuador; e o interruptor como dispositivo para abrir ou fechar o circuito elétrico. Nessa aula o circuito foi unido com a primeira parte desenvolvida anteriormente e com o suporte do protótipo feito com palitos. Além dos objetivos centrais da atividade e o enriquecimento dos assuntos relacionados, as crianças desenvolvem suas habilidades criativas, aprendem a seguir roteiros e a ir além destes, incrementando a partir da sua capacidade inventiva.

\subsubsection{Conceitos sobre Montagem 3D}

Outra atividade desenvolvida para o quinto ano foi a montagem de um quebra cabeça 3D de madeira, no formato de dragão, criado na impressora a laser. A princípio foi tratado sobre o espaço tridimensional e a transformação de peças $2 \mathrm{D}$, com apenas altura e largura em um objeto único em 3D, com altura largura e profundidade. 
VII Congresso Brasileiro de Informática na Educação (CBIE 2018)

Anais do XXIV Workshop de Informática na Escola (WIE 2018)

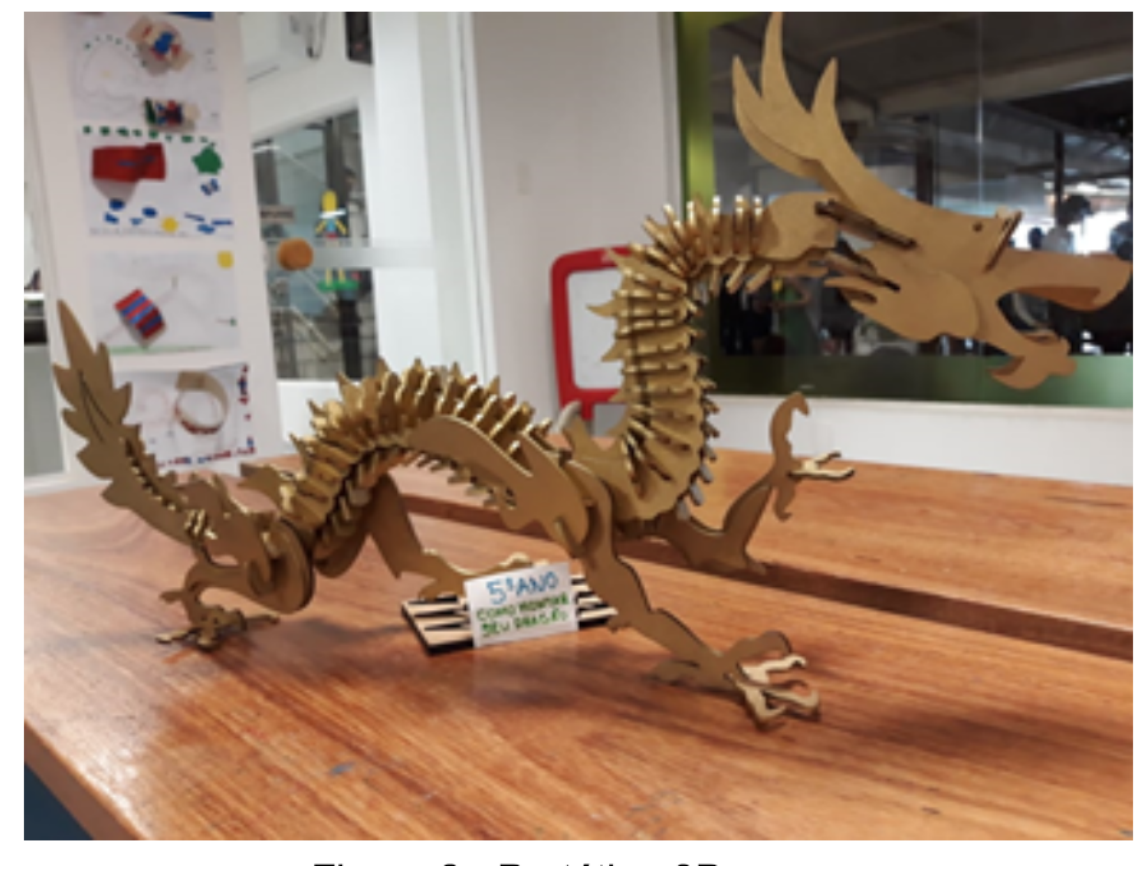

Figura 2. Protótipo confeccionado em 3 dimensões.

Essa atividade permite que os alunos entendam o conceito das três dimensões, desenvolvam atenção, raciocínio lógico, atuem com a memória, motivando a habilidade de observar, comparar e se comunicar em grupo para garantir a eficiência dos seus resultados, desenvolvendo suas inteligências e estimulando a aprendizagem.

\subsection{Quarto ano}

\subsubsection{Conceitos sobre Propulsão}

Um dos projetos desenvolvidos no quarto ano foi a criação do protótipo de uma Mini Catapulta. Essa aula relacionou o funcionamento da catapulta e os conceitos físicos de armazenar e liberar energia para o lançamento de projéteis. Foi utilizado para fins didáticos uma torre de copos, a qual os alunos após a prototipagem estariam realizando testes em formato de game. O objetivo era derrubar o máximo de copos possíveis com a ferramenta criada, sendo que cada copo tinha uma pontuação diferente por cor.

Os alunos criaram o objeto individualmente, seguiram um roteiro de construção e logo após puderam fazer o teste do seu lançador acertando a torre de copos. Ao fazerem os testes os alunos puderam entender de forma didática o conceito de movimento oblíquo, ângulo, eixo x, eixo y e queda livre trazendo uma percepção para acertarem mais pontos com os lançamentos.

Essas atividades bem como as demais, seguiram a proposta pedagógica do uso de materiais para possibilitar experiências com a produção de protótipos. Permitiu a interação entre a classe, o compartilhamento dos materiais e o desenvolvimento da linguagem no momento de resolver conflitos e tomar decisões. 
VII Congresso Brasileiro de Informática na Educação (CBIE 2018)

Anais do XXIV Workshop de Informática na Escola (WIE 2018)

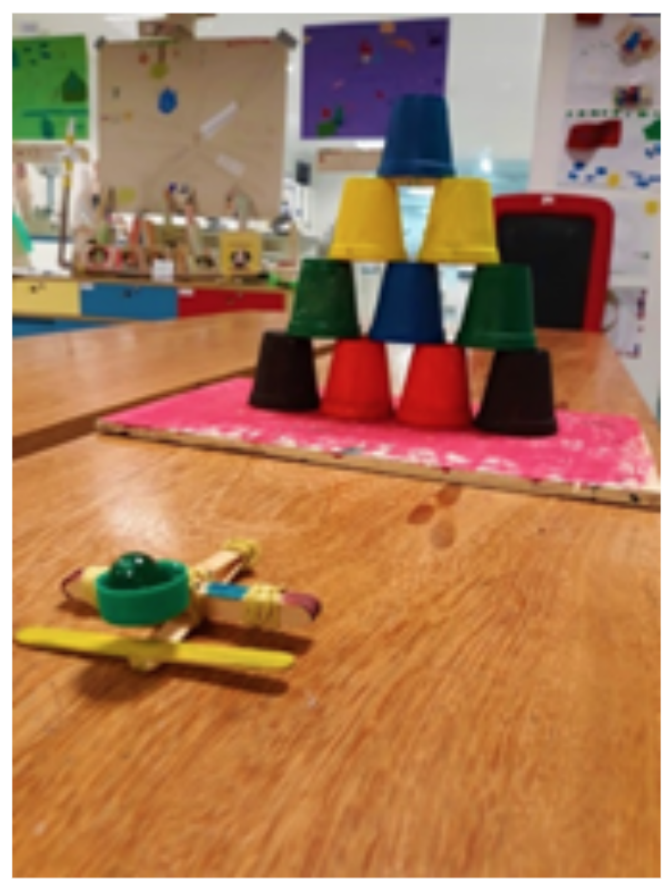

Figura 3. Protótipo confecionado para apresentação dos conceitos sobre propulsão.

\subsubsection{Bonecos com LED}

Com os estudantes do quarto ano foi realizada uma atividade para relacionar engenhosidade, inovação, e trabalho em grupo colocando a mão na massa. Inicialmente foi apresentada a plataforma de prototipagem Arduino, com a apresentação eles entenderam que a partir de ferramentas computacionais é possível enviar comandos para uma plataforma e criar ferramentas tecnológicas. Entenderam o funcionamento dos pinos do arduino relacionando com os polos positivo e negativo do LED.

Divididos em grupo, os alunos tiveram que esboçar o animal que eles iriam desenvolver com massa de modelar, permitindo que praticassem sua capacidade de inovação e construção coletiva. Executaram o que foi planejado no esboço e fizeram as conexões dos leds no arduino. As atividades propõe aos alunos o constante interesse por desafios e interação com a tecnologia e com o grupo, além de outros aspectos que se configuram nesse contexto.

\section{Conclusões e Considerações Finais}

$\mathrm{O}$ uso de tecnologia aplicada à educação alinhado à cultura Maker de trabalho em grupo e mão na massa, trouxe para os alunos a capacidade de compreender conceitos relacionados a ciência, desenvolver capacidade de se relacionar, entre outras habilidades cognitivas e comportamentais que se perpetuarão durante sua vida. Essa temática proporciona um incentivo à pesquisa e inventividade, além de motivar o interesse dos alunos pela arte e ciências. Para os alunos a aula se torna mais prazerosa, e eles passam a gostar ainda mais do ambiente escolar. O desenvolvimento das habilidades citadas provoca no aluno uma atitude investigativa diante dos assuntos ensinados em sala e diante das situações vivenciadas. 
VII Congresso Brasileiro de Informática na Educação (CBIE 2018)

Anais do XXIV Workshop de Informática na Escola (WIE 2018)
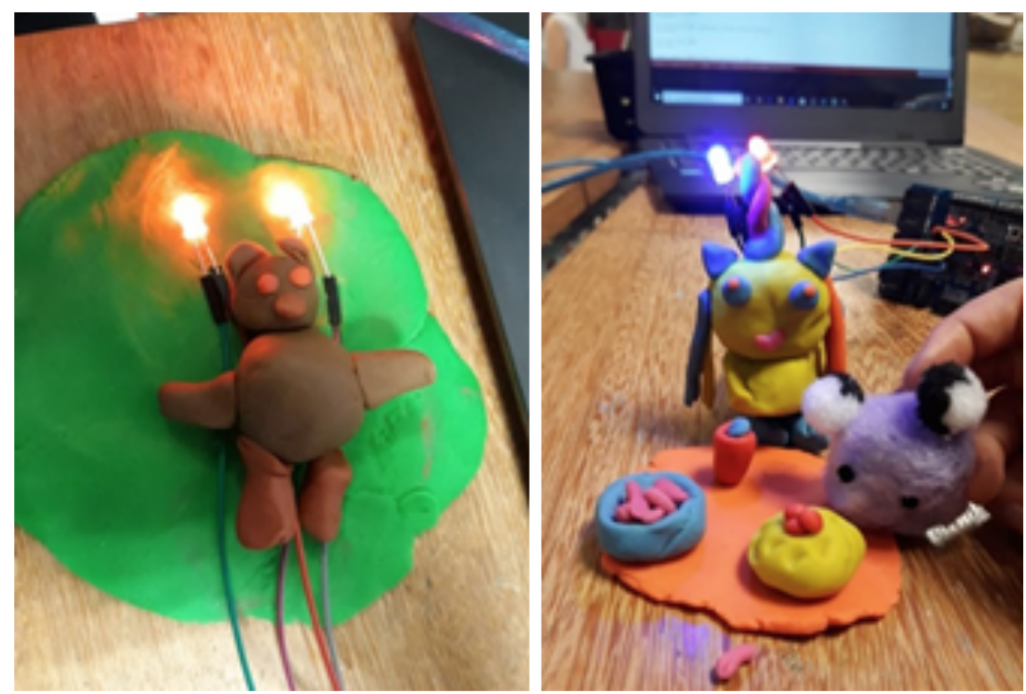

Figura 4. Atividades desenvolvidas com microcontrolador Arduino.

É perceptível que a cultura Maker não influencia apenas nos aprendizados teóricos, não proporciona apenas uma ligação com os assuntos que são ou serão ministrados em sala, mas também provoca uma mudança de postura do aluno, tornando-o mais curioso e apto para questionar, inovar e produzir. Aprimora sua capacidade de percepção, investigação, raciocínio lógico e engenhosidade. A cultura Maker é uma forma de preparar os alunos para enfrentar os desafios do século XXI. O ensino tradicional de muita teoria e exercícios possui um modelo que atende a demandas antigas, enquanto nos dias atuais é extremamente necessário o uso de estratégias que estimulem o desenvolvimento das competências citadas acima, a capacidade de projetar, e construir uma cidadania digital.

Atualmente utilizamos a tecnologia e a ciência para tudo! Para que os alunos se tornem adultos com as competências profissionais necessárias é preciso que não apenas saibam utilizar tais tecnologias, mas dominem o funcionamento destas, a começar desde cedo, com atividades simples, mas que geram aprendizado e busca por preparação para essa realidade. Entender o funcionamento das tecnologias ajuda a entender o mundo que estamos vivendo, tudo isso através de uma linguagem lúdica e de fácil compreensão para o nível de cognição das crianças.

É possível afirmar que ao longo do projeto relatado, os resultados foram positivos. Com a vivência dos projetos no Maker é possível perceber a necessidade de repensar o ambiente físico escolar, a forma de ensino, a capacitação de professores e a conscientização dos pais sobre a necessidade de investir na utilização desses meios para revolucionar a educação. É fundamental ter mentalidade aberta para abraçar os programas educacionais tecnológicos e novos métodos de ensino em sala. É indispensável a criação de políticas públicas para que esse novo método de ensino seja disponibilizado para todos. Investimentos em educação desde o começo da vida escolar é essencial, pois quanto mais cedo a criança tem contato com essa realidade, maior a possibilidade de desenvolvimento e um bom futuro, contribuindo de fato para o desenvolvimento econômico do país.

A aplicação da tecnologia no Ensino Fundamental 1, busca aproveitar dessa pre- 
VII Congresso Brasileiro de Informática na Educação (CBIE 2018)

Anais do XXIV Workshop de Informática na Escola (WIE 2018)

missa para incentivar as crianças a resolverem problemas, serem criativas, saibam se comunicar, colaborar, trabalhar em grupo, tenham um pensamento crítico e inovador, saibam gerir seu tempo, desenvolver projetos.Dessa forma é possível que as crianças sejam ativos no processo de inovação da sociedade, busquem soluções em favor do coletivo e tenham um raciocínio empreendedor.

\section{Referências}

Buckingham, D. (2007). Crescer na era das mídias eletrônicas, volume 1. Loyola.

Cheroglu, S. (2014). Educação e desenvolvimento de zero a três anos de idade. Dissertação de Mestrado, Universidade Estadual Paulista Júlio de Mesquita Filho.

de Alencar, E. M. L. S. (2003). Contribuições teóricas ao estudo da criatividade. Revista Psicologia: Teoria e Pesquisa, pages 1-8.

Duarte, A. S., Sanches, R. A., and Dedini, G. F. (2017). Do movimento maker à customização em massa: $\mathrm{O}$ uso das tecnologias da informação e comunicação na indústria têxtil e de confecção. 11h Congresso Brasileiro de Inovação e Gestão de Desenvolvimento do Produto, pages 1-10.

Machado, E. and Adalberto, L. (2016). Movimento makers e a aprendizagem criativa no ensino da matemática no fundamental 1. Educação Matemática na Contemporaneidade: desafios e possibilidades, pages 1-8.

Martins, J. S. (2001). O trabalho com projetos de pesquisa: do ensino fundamental ao ensino médio, volume 1. Editora Papirus.

Piaget, J. (1986). O nascimento da inteligência da criança, volume 1. Editora Crítica.

Piaget, J. (2011). Seis estudos de Piaget, volume 1. Editora Rio de Janeiro: Forense Universitária.

Pinto, S. L. U., Pinto, S. L. U., Santos, G. S. P., Hamad, A. F., and Teixeira, C. S. (2016). O movimento maker: Enfoque nos fablabs. 26th Conferência ANPROTEC, pages 1-16.

Rafaela Samagaia, D. D. N. (2015). Educação científica informal no movimento maker. EX Encontro Nacional de Pesquisa em Educação em Ciências ENPENC, pages 1-8.

Vygotski, L. (1987). Pensamento e Linguagem Superiores, volume 1. Editora Martins Fontes.

Vygotski, L. (1998). A Formação Social da Mente: O Desenvolvimento dos Processos Psicológicos Superiores, volume 6. Editora Martins Fontes. 